\title{
Control system design and model development for a ducted-fan singlecopter
}

\author{
Nguyen Hoang Thien, Nguyen Trong Nghia, Huynh Van Kiem
}

\begin{abstract}
This paper proposes to design the ducted-fan singlecopter, a new kind of vertical take off and landing (VTOL) device with promising applications. As its most basic level, the singlecopter is a device features a single propeller that produces thrust and a set of four wings to control navigation and flight maneuvers. In recent years, a growing interest has been clearly shown in both academic researches and industry for aerial platforms, for the purpose of replacing men in dangerous or onerous situations. The singlecopter is a small ducted-fan VTOL unmanned aerial vehicle (UAV), which has roughly the same dimensions as a soccer ball and can stay hover for up to 15 minutes in narrow structures such as hallways and tunnels. With its ducted-fan VTOL shape, singlecopter can land safely on the ground in any position and tumble around dangerous obstacles and debris. The flight controller hardware, controller software, as well as mechanical frame for the singlecopter was developed from the ground up. The final singlecopter system is able to maintain flight stability and follow the control of roll, pitch, yaw angle.
\end{abstract}

Index Terms - Aerial Robotics, UAV, VTOL, Ducted-Fan, Singlecopter.

\section{INTRODUCTION}

$\mathrm{I}$ $\mathrm{n}$ these last years, a growing interest has been shown in robotics. In fact, several industries (automotive, medical, manufacturing, space...),

Manuscript Received on March 15 ${ }^{\text {th }}$, 2017, Manuscript Revised on November $0^{\text {st }}$, 2017.

Nguyen Hoang Thien, Faculty of Electrical \& Electronics Engineering, Ho Chi Minh City University of Technology, Vietnam National University - Ho Chi Minh City, Vietnam (email: 41203579@hcmut.edu.vn)

Nguyen Trong Nghia, Faculty of Electrical \& Electronics Engineering, Ho Chi Minh City University of Technology, Vietnam National University - Ho Chi Minh City, Vietnam.

Huynh Van Kiem, Faculty of Electrical \& Electronics Engineering, Ho Chi Minh City University of Technology, Vietnam National University - Ho Chi Minh City, Vietnam (email: hvkiem@hcmut.edu.vn). require robots to replace men in dangerous, boring or onerous situations. A wide area of this research is dedicated to aerial platform. One valuable new resource being developed for today's soldier are small ducted-fan vertical takeoff and landing (VTOL) unmanned aerial vehicles (UAVs), often called "singlecopter", as shown in Fig. 1. A camera can be used for mobile target tracking or environment mapping ${ }^{[1]}$. Fig. 2 illustrates the overview system structure.

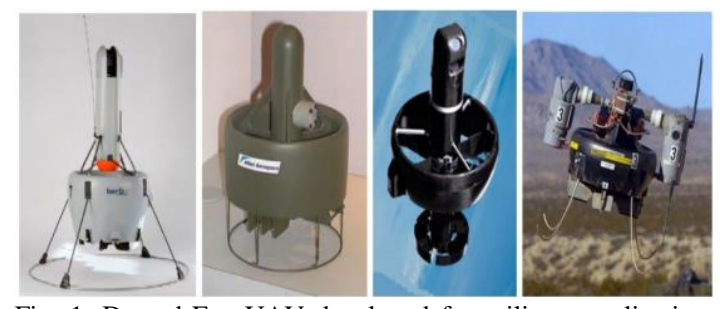

Fig. 1. Ducted-Fan UAV developed for military applications (from left to right): Hovereye, iSTAR. FanTail. Honeywell THawk. These designs focused on material and endurance for battlefield usage.

The singlecopter has various capabilities over other kinds of UAV: the ability of taking off and landing without the need for a runway; unlimited hovering capability to land on top of buildings in battlefield or urban areas. The ducted-fan configuration also provides aerodynamic advantages to generate more lift due to the duct effect. Operation modes of singlecopter can be classified by three modes as hover, transition, and cruise modes. Therefore, an operation concept takes these advantages into account. For instance, the vehicle vertically takes off from an unmanned ground vehicle (UGV) or a military jeep and goes up to proper altitude, when the ducted-fan UAV is operated in the battlefield for a reconnaissance mission.

Although beneficial in many ways, one major operational problem of ducted fan vehicles is precise control when flying. In this paper, a PID controller based on new control theory developed 
for singlecopter system is proposed considering possible flight conditions. Our work also focused on modification of hardware to generate and access required signals, functions programming and implementation of control equations developed in previous thesis works.

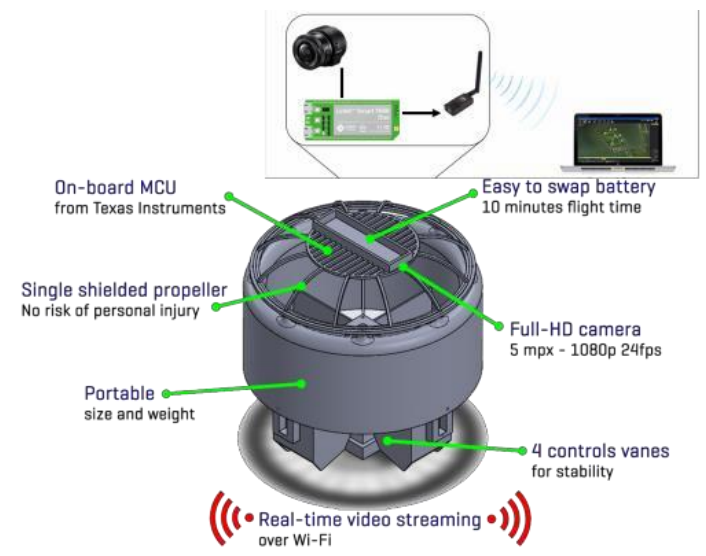

Fig. 2. Singlecopter System Overview and Features

\section{SingleCOPTER SySTEM OVERVIEW}

\subsection{Advantages of Ducted-Fan UAV VTOL}

Ducted-Fan UAVs with VTOL (Vertical TakeOff and Landing) capability provide many advantages compare to their equivalent fixed-and open-wing counterparts. When it comes to safety, payload, and scalability, the ducted fan UAV has proven many advantages: shrouded frame prevents the user from risk or injury; the ducted fan UAVs maintain a higher payload to vehicle ration (singlecopter can carry $4 \mathrm{x}$ the payload of a similar footprint fixed- or open-wing UAV); the singlecopter are easily scaled to specific missions or applications.

\subsection{IMU System Overview}

An inertial measurement unit, or IMU, is an electronic device that measures and reports on object's velocity, orientation, and gravitational forces, using a combination of accelerometers and gyroscopes, sometimes also magnetometers $[1,2]$. An inertial measurement unit works by detecting the current rate of acceleration using one or more accelerometers, and detects changes in rotational attributes like pitch, roll and yaw using one or more gyroscopes. And some also include a magnetometer, mostly to assist calibrate against orientation drift $[1,4]$. To smoother the IMU data and orientation angle, a filter is required. After implementing on real hardware system and comparing results, Madgwick AHRS filter was used since it is able to deliver results similar to Kalman without the high computational costs. The block diagram of the Madgwick AHRS filter is shown in Fig. 3.

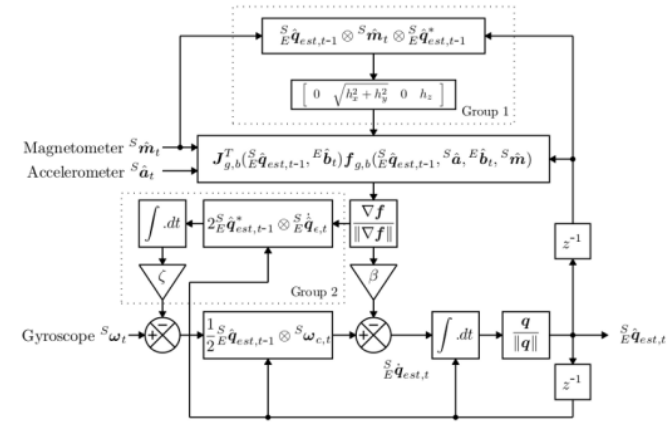

Fig. 3. Block Diagram of the Madgwick AHRS filter

\subsection{Mechanical System}

Fig. 4 shows the mechanical configuration and design of the singlecopter. The singlecopter mechanical system consists of four control surfaces that are located at the end of the duct. Also, it contains fixed stators for reducing an antitorque effect and additional lift. A fuselage is in center of the vehicle, where electronic controllers and peripherals are mounted. For various missions, operating equipment such as camera and spot light and communication relay can be located at this position.

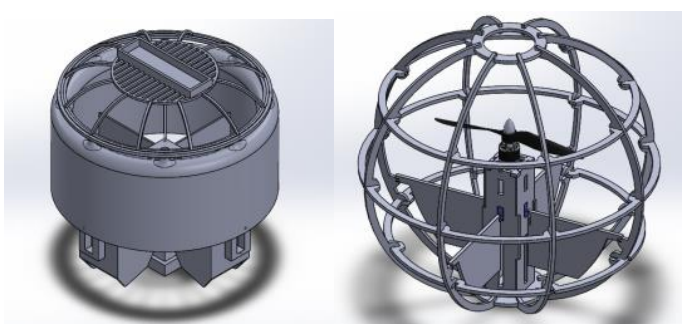

Fig. 4. Mechanical configuration for singlecopter - ducted (left) and open (right) frame

A coordinate system shown in Fig. 5 has dynamic features similar to a helicopter: thrust vector, antitorque effect, gyroscopic coupling, and velocity induced by a main rotor. Pitch angle and angle of attack are zero at hover flight: as the vehicle goes forward, it becomes negative ${ }^{[13]}$. In addition, moment of inertia is completely the same about span because of symmetricity. The control surfaces are defied as in Fig. 4: the control surfaces 1 and 3 are ailerons, 2 and 4 are elevators, and deflecting all of control surfaces are rudders. These surfaces deflect from -30 to +30 degrees. 
An additional goal of this research is to use the stabilized singlecopter system for practicle uses by attaching a live feed camera to the frame. Creating a stable good quality aerial clip has been a challenge for any UAV system. This technology can be used for search and rescue, firefighting, law enforcement, military, news reporting etc. The end result of producing a digital video signal will allow for future expansions such as UAV sentience, target tracking, obstacle avoidance, and many more.

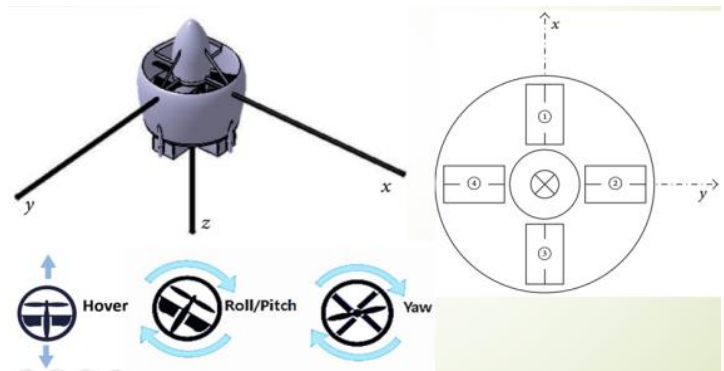

Fig. 5. Coordinates for the singlecopter frame (left, top), control surfaces definition (left, down), and movement control surfaces (right)

\section{MATHEMATICAL MODEL}

The dynamics of a generic 9 degrees of freedom (DOF) rigid-body takes into account the mass of the body $m[\mathrm{~kg}]$ and its inertia matrix $\boldsymbol{I}[N$ $m s 2]$ is described by the following equation [3, 4]:

$$
\left[\begin{array}{cc}
m I_{3 \times 3} & 0_{3 \times 3} \\
0_{3 \times 3} & I
\end{array}\right]\left[\begin{array}{c}
\dot{V}^{B} \\
\dot{\omega}^{B}
\end{array}\right]+\left[\begin{array}{c}
\omega^{B} \times\left(m V^{B}\right) \\
\omega^{B} \times\left(I \omega^{B}\right)
\end{array}\right]=\left[\begin{array}{c}
F^{B} \\
\tau^{B}
\end{array}\right]
$$

The generic equation of the 9-DOF rigid- body equation derived with the Newton-Euler formalism is [4]:

$$
\begin{aligned}
& \dot{u}=v r-w q-g \sin \theta+\frac{\left(X_{\text {fuse }}+X_{\text {duct }}+X_{c s}\right)}{m} \\
& \dot{v}=p w-u r+g \sin \phi \sin \theta+\frac{\left(X_{\text {fuse }}+X_{d u c t}+X_{c s}\right)}{m} \\
& \dot{w}=u q-v p+g \cos \phi \cos \theta \\
& \quad+\frac{\left(Z_{\text {fuse }}+Z_{\text {rotor }}+Z_{\text {duct }}+Z_{\text {stator }}+Z_{c s}\right)}{m} \\
& \dot{p}=\frac{p r\left(I_{y y}-I_{z z}\right)}{I_{x x}}+\frac{\left(L_{\text {fuse }}+L_{d u c t}+L_{\text {gyro }}+L_{c s}\right)}{I_{x x}} \\
& \dot{q}=\frac{p r\left(I_{z z}-I_{x x}\right)}{I_{y y}+\frac{\left(M_{\text {fuse }}+M_{\text {duct }}+M_{\text {gyro }}+M_{c s}\right)}{I_{y y}}} \\
& \dot{r}=\frac{\left(N_{\text {gyro }}+N_{\text {rotor }}+N_{\text {stator }}+N_{c s}\right)}{I_{z z}}
\end{aligned}
$$

\section{SYSTEM IMPLEMENTATION}

\subsection{System Architecture}

The singlecopter is a complex mechanical system, it collects numerous physical effects from the aerodynamics and the mechanics domains. The model of singlecopter should consider all the important effects including the gyroscopic ones. In this work, the Newton - Euler formalism and the Euler angles theories have been chosen, as mentioned in previous section. The model information of the singlecopter with physics and derivations is rather complex and will not be presented in this thesis paper [4], but used from previous works as a base for developing new system.

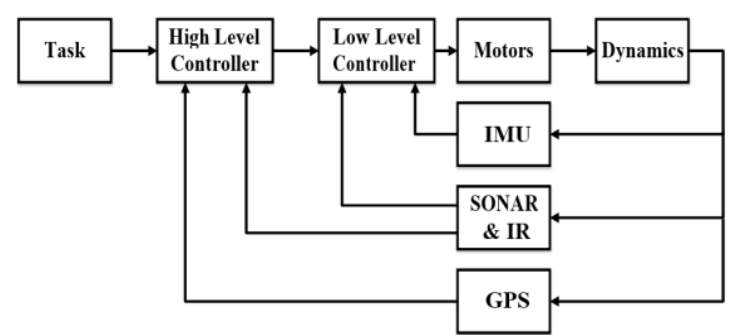

Fig. 6. Singlecopter's system architecture

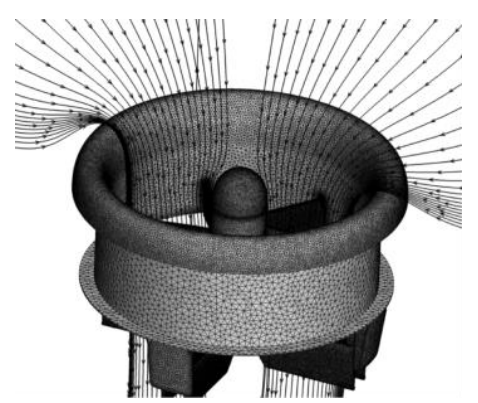

Fig. 7. Aerodynamic effect of ducted-fan. The thrust is increased, but only if the distance between the tip of the propeller and the duct's wall is lessthan $0.2 \mathrm{~mm}$.

The task block represents the goal of the singlecopter. It is "provided" by the user through wireless communication. Both the high level and low level controller block is implemented on the ARM Cortex-M4 MCU. The high level provides with trajectory planning and obstacle avoidance. Its main task is not to stabilize the singlecopter, but to make it navigate with safety.

\subsection{Mechanical Design}

Several different mechanical configurations were tested that were beyond the scope of this paper, yet still provide useful information. Below are designs of duct frame, both the box vanes and opposed vanes. The primary objective was still to 
find which configuration offered the most overall control authority with a relatively simple, practical design.
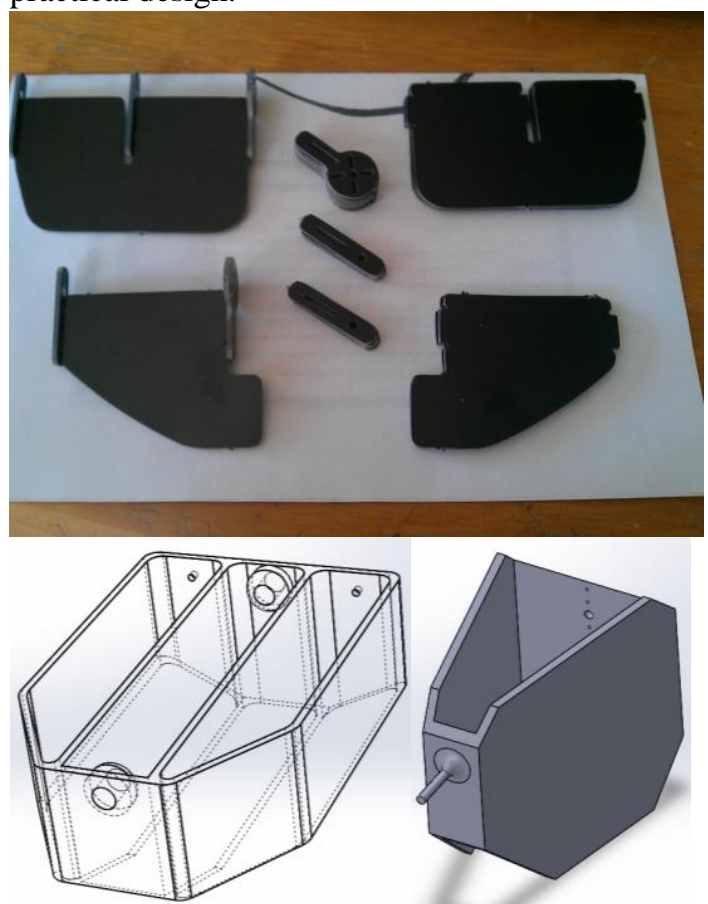

Fig. 8. Control vanes design: box vane (top image, left), fuselage (top image, right), flap surfaces (bottom)

The additional weight of both the linkage system and the duct also counteracts the improved performance. The open duct and center-flap configuration was therefore selected for its combination of performance, light weight, and simple design. An iteration of the duct design has been conducted to optimize the duct once integration aspects of other systems (controller, surface vane, mechanical frame etc.) are determined. If the original duct needs to be modified to achieve performance goals, then additional design trade-offs will be undertaken.

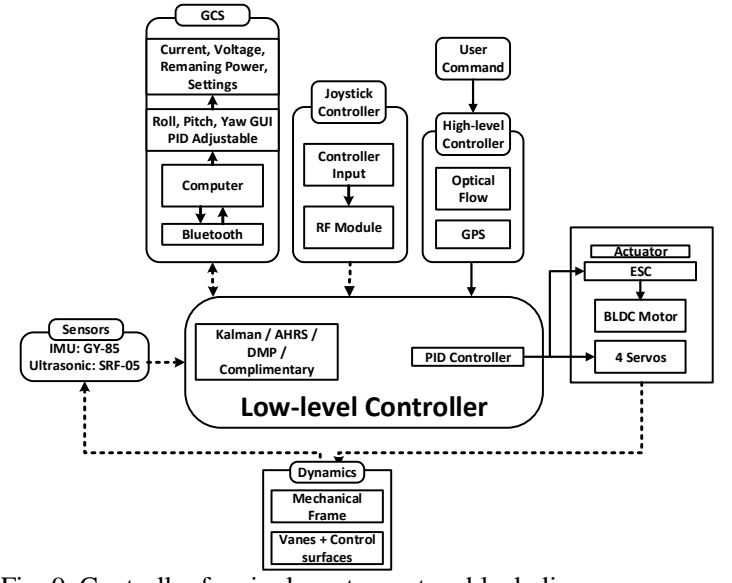

Fig. 9. Controller for singlecopter system block diagram

TABLE 1

PARAMETER COMPARISON BETWEEN BLDC MTORS

\begin{tabular}{|c|c|c|c|c|}
\hline Model & $\begin{array}{c}\text { Emax } \\
850 \mathrm{KV} \\
\text { Outrunner } \\
\text { Brushles } \\
\text { s Motor }\end{array}$ & $\begin{array}{c}\text { SunnySky } \\
\text { V3508 } \\
\text { Brushless } \\
\text { Motor }\end{array}$ & $\begin{array}{c}\text { NTM } \\
\text { Prop } \\
\text { Drive 28- } \\
36 \\
1400 \mathrm{KV} / \\
560 \mathrm{~W}\end{array}$ & $\begin{array}{c}\text { SunnySky } \\
\text { X2216- } \\
1100 K V\end{array}$ \\
\hline $\begin{array}{c}\mathrm{KV} \\
(\mathrm{rpm} / \mathrm{V})\end{array}$ & 850 & 580 & 1400 & 1100 \\
\hline $\begin{array}{l}\text { Weight } \\
(\mathrm{g})\end{array}$ & 182 & 107 & 86 & 72 \\
\hline $\begin{array}{l}\text { Max } \\
\text { Currrent } \\
\text { (A) }\end{array}$ & 61 & 16.4 & 45 & 21 \\
\hline Pull (g) & 2650 & 1610 & 1480 & 1320 \\
\hline $\begin{array}{l}\text { Shaft } \\
(\mathrm{mm})\end{array}$ & 5 & 6 & 4 & 3.175 \\
\hline $\begin{array}{l}\text { Suggested } \\
\text { Propeller }\end{array}$ & $13 \times 6.5$ & $15 \times 5$ & $8 \times 4$ & $9 \times 4.5$ \\
\hline
\end{tabular}

Motor SunnySky X2216 was selected for the development of the singlecopter due to its highest pull / weight and current consumption.

\subsection{Flight Controller Block Diagram}

Based on Fig. 6, the singlecopter system consists of the following parts. All the devices and boards are reported in a block diagram below to visualize their interconnections. In this system, the ARM Cortex-M4 microcontroller is the brain since it organizes the communications of all devices. The peripherals interface and timing is moreover a delicate issue. The software code and architecture must use the MCU's ability to its limit to keep the whole system under control and stabilize the singlecopter's movements. 


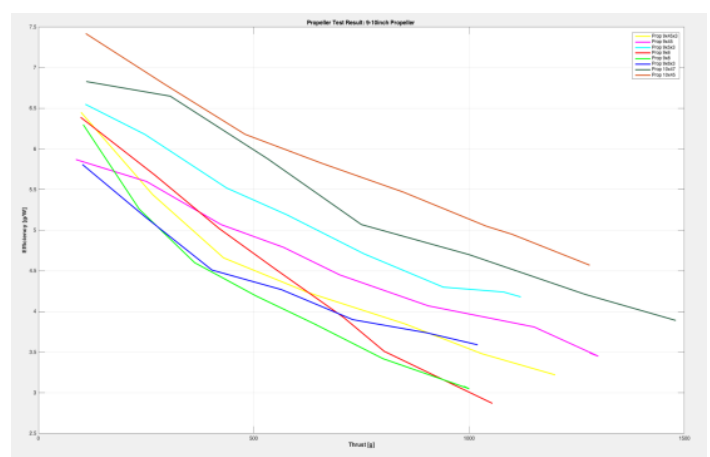

Fig. 10. The motor is tested for thrust power, total power consumption and efficiency, with different propeller sizes.

The proposed controller scheme will be applied for an experimental system. ARM Cortex-M4 MCU provides competitive features and a lot of built-in peripherals. For this reason, it is possible to expand the project with other devices and functionalities.

\subsection{Thrust Motor Selection}

The following requirements are set out to build the singlecopter system: total mass $<800 \mathrm{gr}$, flight time $>10$ mins. The BLDC motors available on the market that fits in those criteria are then tested for their maximum pull weight, current rating, efficiency etc. Comparison results are shown in table 1. Selection of thrust motor is mandatory for development of singlecopter, because duct, vanes, battery etc. is limited by the overall weight limit of the system. After the motor is selected, it is tested for maximum thrust power and efficiency with different propeller sizes, as shown in Fig. 10.

\section{SOFTWARE DEVELOPMENT}

The software structure of the algorithm can be simplified as shown in Fig. 11. Four DOFs ( $\mathrm{x}, \mathrm{y}$, $\mathrm{z}$, yaw) must be controlled with the help of an absolute reference to achieve stable hovering. The Singlecopter controller only receives filtered and fused sensor data from the low-level processor and performs accordingly.

In this thesis, a ground station was developed to display real-time data on the singlecopter's performance and position. A ground station is typically a software application, running on a ground-based computer, that communicates with the UAV via bluetooth telemetry. It can also be used to upload new commands to the singlecopter in flight and set new parameters, as shown in Fig. 12.

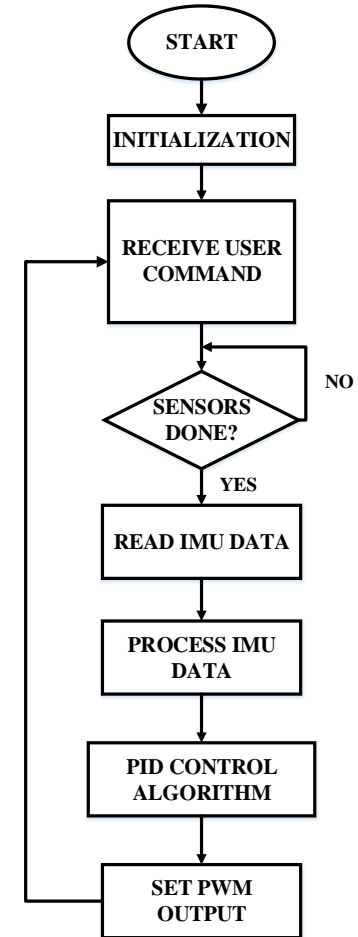

Fig. 11. Singlecopter control algorithm flowchart.

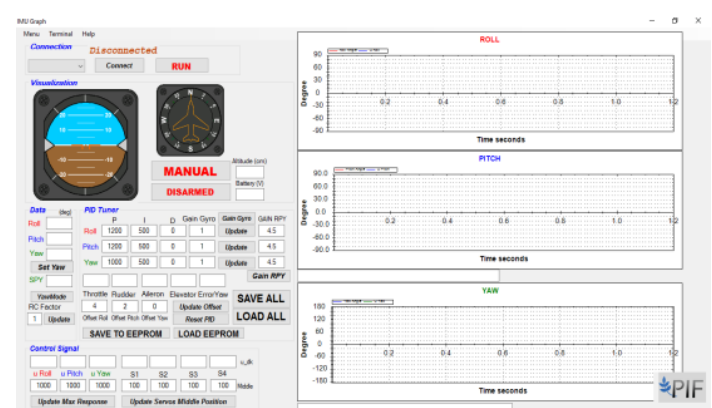

Fig. 12. Graphical User Interface (GUI) for ground control station

\section{RESULTS}

Stable hovering with the singlecopter was achieved with the system described above. To get better controller's performance, new acceleration measurements were used as well as the differential terms from previous data readings as inputs for Madgwick AHRS filter. This also avoids delays induced by bluetooth transmission to human station. singlecopter system is able to respond quickly based on the onboard velocity estimates whereas drift resulting from integrating noisy signals is compensated.

During development, several prototypes of singlecopter were tested to learn the effect of the duct, the vanes, and mechanical configuration on singlecopter's performance, shown in Fig. 13. 


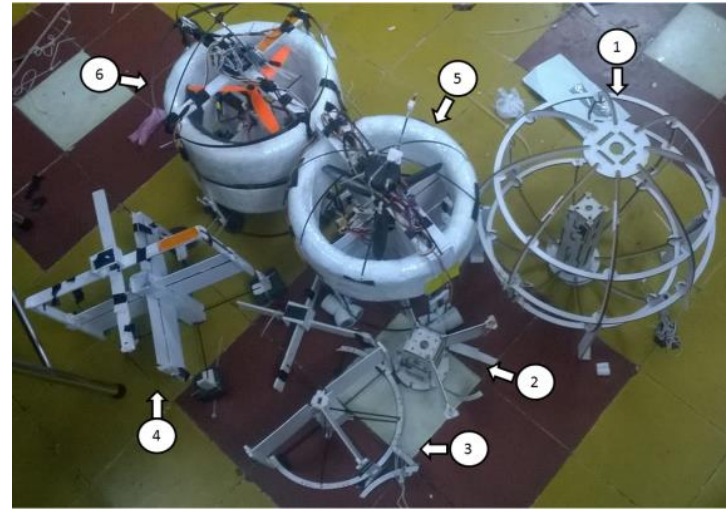

Fig. 13. Development prototypes for the ducted-fan singlecopter. The configuration tested includes: open protected frame with no duct, no static vanes (1) and with static vanes (2), (3), (4), ducted-fan frame with lowest profile (5) and ducted-fan with best performance profile (6).

Fig. 14 demonstrates the flight controller for singlecopter's ability to achieve desired performance for an UAV: anti-rotation for yaw (antitorque) when taking off and hovering, stable flight with maximum $500 \mathrm{~ms}$ delay between control and response angle, maintain stability during in-house flight and outdoor with light wind condition. The yaw angle control scheme needs more experiment to get better performance.

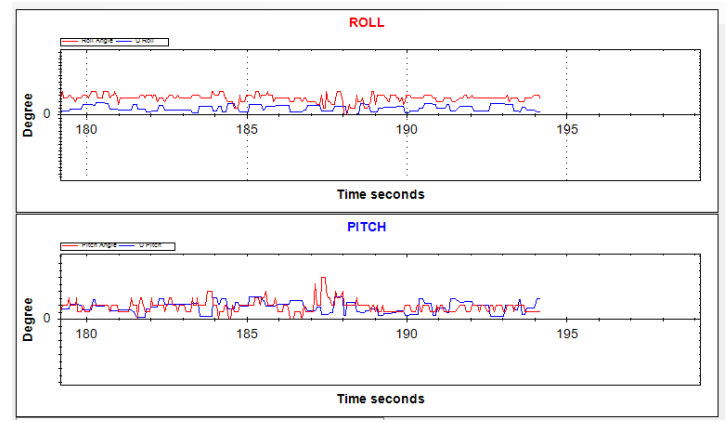

Fig. 14. Control response for roll and pitch angle in test flight. The control scheme used is PID. There is a $500 \mathrm{~ms}$ delay from control signal to response angle, due to singlecopter's aerodynamic features.

\section{CONCLUSION}

This paper has examined the different aspects needed in order to develop a flight controller used for a singlecopter in ducted fan configuration. Based on analysis, the system was implemented on a microcontroller using a variety of sensors. This allowed a person to operate and fly the singlecopter in several different modes depending on the gesture input. An Android application were also written allowing different parameters to be adjusted easily. The singlecopter has been designed such that transmission loss and time delay when using manual $\mathrm{RC}$ remote control would be overcome.

\section{REFERENCES}

[1]Junho Jeong, Seungkeun Kim, Jinyoung Suk, “Control System Design for a Ducted-Fan Unmanned Aerial Vehicle Using Linear Quadratic Tracker," in International Journal of Aerospace Engineering, vol. 15, no. Article ID 364926, 2015.

[2]Johnathan Flemming, Troy Jones, "Improving Control System Effectiveness for Ducted Fan VTOL UAVs Operating in Crosswinds," in AIAA "Unmanned Unlimited" Systems, Technologies, and Operations Aerospace, $2^{\text {nd }}$ ed., San Diego, California, 2003.

[3]Sagar Bose, Rohan Verma, Kriti Garuda, "Modeling, analysis and fabrication of a thrust vectoring spherical VTOL aerial vehicle," in 2014 IEEE Aerospace Conference, 2014.

[4]R. Harris, "Investigation of Control Effectors for Ducted Fan VTOL UAVs," Master Thesis, Blacksburg, Virginia, 2007.

[5]T. D. Anh, H. N. Vinh, "DCM-based orientation estimation using cascade of two adaptive extended Kalman filters," in 2013 International Conference on Control, Automation and Information Sciences (ICCAIS), Nha Trang, 2013.

[6]Hui Wen Zhao, "Development of a Dynamic Model of a Ducted Fan VTOL UAV," Master's Thesis, RMIT University, Melbourne, 2009.

[7] Y. H. Choi, J. Suk, S.-H. Hong, "Static analysis of a small scale ducted-fan UAV using wind tunnel data," in International Journal of Aeronautical and Space Sciences, vol. 13, no. 1, 2012, pp. 34-42.

[8]Eric N. Johnson, Michael A. Turbe, "Modeling, Control, and Flight Testing of a Small Ducted Fan Aircraft," AIAA J. Guidance, Control, Dynamic, vol. 29, no.4, pp. 769779, 2006.

[9]Nguyen Vu Gia Bao, Phan Dang Khoa, "Tracking Control and Embedded Image Processing for Autopilot Hexacopter," in Proceedings of VNU-HCMUT FEEESRC, 2015, pp. 65-70.

[10] J. M. Pflmlin, P. Soueres, T. Hamel, "Position control of a ducted fan VTOL UAV in crosswind," International Journal of Control, vol. 80, no. 5, 2007, pp. 666- 683.

[11]P. J. Moran, "Control Vane Guidance for a Ducted-Fan Unmanned Air Vehicle," Thesis, Naval Postgraduate School, Monterey, California, 1993.

Nguyen Hoang Thien received the B.Eng degree in Control Engineering and Automation from Ho Chi Minh City University of Technology, VNUHCM, Vietnam in 2017.

$\mathrm{He}$ is currently working as a researcher at the Nanyang Technological University Singapore. His research interest includes the development of UAV and unmanned system, robotics and control. 
Nguyen Trong Nghia is currently in the final year of his B.Eng degree in Control Engineering and Automation at the Ho Chi Minh City University of Technology, VNU-HCM.

His research interest includes UAV development and design, localization and navigation, robot - human interaction.
Huynh Van Kiem was born in Vietnam in 1954. $\mathrm{He}$ received the B.Eng and M.Eng degrees in control engineering.

$\mathrm{He}$ is currently working as a senior lecturer at the Falcuty of Electrical and Electronics Engineering, Ho Chi Minh City University of Technology, VNU-HCM, Vietnam.

\title{
Thiết kế, nghiên cứu, chế tạo mô hình máy bay một cánh quạt Singlecopter
}

\author{
Nguyễn Hoàng Thiện, Nguyễn Trọng Nghĩa, Huỳnh Văn Kiểm
}

\begin{abstract}
Tóm tắt - Bài báo trình bày nghiên cứu về đối tượng máy bay một cánh quạt - Singlecopter. Thuộc dạng máy bay VTOL (Vertical Take Off and Landing - cất cánh, hạ cánh theo chiều thẳng đứng), singlecopter là một thiết bị bay độc đáo, với một cánh quạt và một motor chính tạo lực nâng, cùng bốn hoặc tám động cơ nhỏ điều khiển các vane hướng luồng khí. Mô hình cơ khí của singlecopter có hai dạng chính: dạng không dùng "ducted fan" với phần frame bên ngoài vừa để giữ cố định các vane hướng khí, vừa bảo vệ an toàn cho người sử dụng, và dạng "ducted fan" với motor và cánh quạt được bọc lại trong một kết cấu hình ống trụ rỗng gọi là "duct" (tương tự hình dáng động cơ phản lực cho máy bay cánh bằng). Trong đó, mô hình Ducted Fan Singlecopter là hướng nghiên cứu chính của đề tài. Mục tiêu chính là nghiên cứu và nắm bắt một cách tổng thể về nguyên lý hoạt động, nguyên lý điều khiển, thiết kế cơ khí và xây dựng được máy bay mô hình một cánh quạt singlecopter, thiết kế và thực hiện bộ điều khiển cân bằng dành cho singlecopter. Yêu cầu của thiết kế cơ khí là đạt các tiêu chí thiết kế về khối lượng, thời gian hoạt động, độ an toàn cho người sử dụng và vận dụng được các đặc tính vượt trội của cấu hình "ducted fan". Yêu cầu của bộ điều khiển là ổn định được các góc nghiêng Roll, Pitch, Yaw của mô hình bám theo tín hiệu đặt. Singlecopter cần có khả năng cất cánh và hạ cánh thẳng đứng dễ dàng, bay ổn định trong môi trường trong nhà và ngoài trời khi có gió nhẹ. Hệ thống còn được trang bị camera và board nhúng để thực hiện những tác vụ xử lý ảnh đơn giản, tạo tiền đề cho những hướng phát triển tiếp theo. Bộ điều khiển cân bằng và hệ thống board nhúng được xây dựng riêng biệt. Ngoài ra một trạm giám sát trên máy tính cũng được xây dựng nhằm quản lý và điều khiển hệ thống từ xa thông qua giao tiếp không dây Bluetooth.
\end{abstract}

Tù khóa- Máy bay không người lái, UAV, máy bay cất cánh và hạ cánh thẳng đứng VTOL, ống dẫn khí ducted fan, singlecopter, IMU. 